\title{
Aspects of Analysis and Synthesis in Design Engineering
}

\author{
W. Ernst Eder \\ Royal Military College of Canada (retired) \\ eder-e@kos.net
}

\begin{abstract}
Engineering aims to provide technical processes (TP) and technical systems (TS) to solve a specific task. Human aspects of designing to establish these TP and TS include action modes, expertise, competencies and the role of information. Aspects of the design process include a methodology that can be applied, and the contrast of synthesis with analysis.
\end{abstract}

\section{Introduction}

Engineering in general has aims that are different to science, the name alone indicates a part of that difference - 'engineering' implies a verb, an activity to produce something useful, 'science' implies a noun, a body of codified knowledge.

Engineering aims to provide processes and technical systems to solve a specific task, to help in performing a desired transformation process, independent of the degree to which the applied phenomena are understood, especially in their interactions. The main regions of activity for engineering are designing, manufacturing/implementing, operating, procuring and supervising. Among these, design engineering as an activity is probably least understood, its investigation only reaches back about 70 years [1,2]. Previous papers have highlighted some aspects $[3,4,5,6,7,8,9]$. Various aspects need to be explored in order to justify the need for students to learn design engineering procedures during their education. A proposed companion paper [9] explores aspects of human action and learning to justify education for systematic and methodical design engineering. This paper explores an overall systematic design process, its constituent of problem solving, and a relationship between the subprocesses of analyzing and synthesizing.

\section{Systematic Engineering Design Process}

As shown in [1,2], the recommended theory-based engineering design process is founded in the model of the transformation system, figure 1. The model declares:

An operand (materials, energy, information, and/or living things - M, E, I, L) in state Od1 is transformed into state $\operatorname{Od} 2$, using the active and reactive effects (in the form of materials, energy and/or information - M, E, I) exerted continuously, intermittently or instantaneously by the operators (human systems, technical systems, active and reactive environment, information systems, and management systems, as outputs from their internal processes), by applying a suitable technology Tg (which mediates the exchange of M, E, I between effects and operand), whereby assisting inputs are needed, and secondary inputs and outputs can occur for the operand and for the operators.

The transformation process, TrfP, in which the operand is transformed, and the five operators, HuS, TS, AEnv, IS and MgtS, are constituent parts of the transformation system, TrfS, and all operators interact to initiate and perform the process.

\section{Figure 1 General Model of a Transformation System [2]}

Once the transformation system shown in figure 1 is understood, designers can develop a theory-based systematic method for a novel system - TP(s) and/or TS(s) - to be designed [1,2,10,11], as follows:

(P1) establish a design specification for the required system, by re-formulating the customers' needs into a full list of requirements [12] as understood by the engineering designer(s), and by obtaining 
agreement with the customers (or their representative) and the management of the manufacturing organization, e.g using the properties/requirements of transformation processes and technical system as guideline [12];

(P2) establish the desirable and required output (operand in state $\mathrm{Od} 2$ ) of the transformation, the ultimate purpose of the product;

(P3) establish a suitable transformation process (structure, with possible alternatives) to change the operand from state Od1 to state Od2, its operations in detail, investigating possible alternative operations and their sequencing, and (if needed) establishing suitable inputs (operand in state Od1);

(P4) decide which of the operations in the transformation process will be performed by humans, and which of them by technical systems, alone or in mutual cooperation with other operators;

(P5) which technical systems (or parts of them) need to be designed at that point (i.e. do not yet exist);

(P6) establish a technology (structure, with possible alternatives) for that transformation operation for which the technical system needs to be designed, and therefore the effects (as outputs) needed from the technical system to cause the transformation;

(P7) establish what the technical system needs to be able to do (its internal and cross-boundary functions, with possible alternatives) to produce these effects/outputs, and what its inputs need to be;

(P8) establish what organs (function-carriers in principle and their structure, with possible alternatives) can perform these functions, and what added (evoked) functions (and organs) are recognized as needed (a function-means chain). A morphological matrix is useful for exploring candidate organs to solve each function, and to allow combining them into organ structures (as concepts). These organs can be found mainly in prior art, especially the machine elements, in a revised arrangement as proposed by Weber $[2,13,14,15,16]$;

(P9) establish with what constructional parts (in sketch-outline, in rough layout, in dimensionaldefinitive layout, then in detail and assembly drawings, with possible alternatives) are needed, and what additional functions (and organs, and constructional parts) are now revealed (evoked) as being needed (a more extended functionmeans chaining), to produce a full description of a future TS(s) in the shortest time and at lowest cost.
Only those parts of this engineering design process that are thought to be useful are employed.

Redesign can be accomplished by:

(Pa) establishing a design specification for the revised system (step P1);

$(\mathrm{Pb})$ analyzing the existing system into its organs and (if needed) its functions (reversing steps (P8) and (P7) of the novel procedure);

(Pc) then following the last one or two parts of the procedure listed above for a novel system.

These model processes cannot be performed in a linear progression, they need iterative and recursive processing, see below.

At each stage and step, a sub-process of problem solving takes place - many times and in rapid iterative repetition in the main cycle, with frequent calls as needed to the three auxiliary processes, see figure 2 . In practice, the individual steps may not be recognizable, they occur routinely, at high speed and essentially in the mind of the designer. The systematic design process appears as ' $\mathrm{H} 1$ ' and ' $\mathrm{H} 2$ ' in figure 2.

\section{Design Processes}

Designing involves planning and executing (or having executed) an envisaged task, including writing, graphical work, products, etc. Design engineering involves predicting and synthesizing a $\mathrm{TP}(\mathrm{s}) / \mathrm{TS}(\mathrm{s})$, which needs compromise and avoidance of conflicts or contradictions in the relationships among individual parts. A new entity is created, with optimal properties for the envisioned transformation process, for which generating alternatives and variants of goals and means, principles and embodiments, is important.

NOTE: 'Designing' should be distinguished from a 'design process'. 'Designing' implies that humans are the only operators performing the process. Yet designers use tools, knowledge of various kinds, and external representations, and are subject to management, and their environments. 'Design process' is more suitable for these transformation processes. 'Design engineering' and 'engineering design process' should be used where the product is a technical system, TS(s), and/or technical process, TP(s). The addition of '(s)' signifies that the TP and/or TS is the subject of the design process. Human cognitive abilities and skills (latent and developing) are essential, a computer alone cannot design. Some artificial intelligence techniques can almost complete designing for some TS (e.g. VLSI electronic chips).

Designing in engineering has the purpose of creating future operating artefacts, $\mathrm{TS}(\mathrm{s})$, and the operational processes, TP(s) for which they can be used, to satisfy the needs of customers, stakeholders and users. These 
Figure 2 Problem Solving [2]

artifacts may be able to actively operate, or to be operated as a tool by a human being. This purpose is accomplished by designing suitable technical means, $\mathrm{TP}(\mathrm{s})$ and/or TS(s), and producing the information needed to realize and implement a product. Designing something useful with a substantial engineering content, usually within market constraints, distinguishes engineering from scientific or artistic activity. Therefore design engineering, combining art, craft and science, is the activity and subject of this paper.

For new or revised products, designing, thinking out, needs smaller stages of progress, in smaller sections (parts, assembly groups). They often need to be recursively sub-divided into smaller 'windows' [17], 'form-giving zones', to re-combine selected alternative solutions.

Design engineering explores alternative solution proposals, and delivers proposals for appearance and presence, and/or manufacturing specifications for a designed product. The output of Design engineering is conventionally a set of manufacturing drawings for constructional parts (or their computer-resident equivalents), assembly drawings, and parts lists. Documentation is needed to demonstrate that performance, strength and durability have been considered, usually by engineering science analysis. For novel design engineering, more abstract elements and structures are usable - transformation processes, technologies, functions, and organs [1,2,10,11]. Creativity also has a role [17], but systematic and methodical designing is preferable [1,2] (but see [9]). Industrial design and design engineering must frequently be coordinated.

Designing is a cognitive-conceptual processing of information, that also contains routine work, and can be supported by prescribed methods. Typical activities include:

(a) analysis, using causality as a premiss, and verbal, graphical and mathematical models - e.g. the engineering sciences;

(b) synthesis, using finality as the aim, including creativity, to find and select among candidate solutions for a TP(s) and/or TS(s);

(c) management to formulate, direct and control activities towards the goals;

(d) decision making, and formulating the criteria for decisions, analyzing, evaluating, selecting and deciding;

(e) problem solving as a detail procedure within designing, searching for information, verifying, checking, reflecting $[18,19,20]$, and making the results of designing useful, representing (e.g. graphically, verbally and/or digitally) and communicating.

The contrast to causality is the concept of finality (purpose determinacy). The goal for finality is to establish a suitable causa finalis, as a future ('as 
should be' state) TP(s) and/or TS(s) intended for that purpose. The goal for the design process is therefore to establish a suitable TS(s)-constructional structure (and other structures). Finality plays the role of a compass to show a direction towards an envisaged goal. The causal relationship intended effect $\longrightarrow$ possible cause $\rightarrow$ optimal cause\} according to finality becomes the relationship $\{$ goal $\longrightarrow$ means $\longrightarrow$ optimal means\}. Designing is always directed towards envisaged goals. Engineering designers look for mainly technical means with which the (intermediate) goal can be reached, problems (inadequacies, defects) can be eliminated, and/or needs fulfilled. The relationship of goals to means expresses the 'finality nexus' (linkage of finality) and represents the process of synthesis starting from the goal, a search for suitable means is performed. Design engineering consists of a sequence of \{goals $\longrightarrow$ means\} transitions, a state of finality. Consequently the leading question for design engineering is 'With what means can one achieve the necessary effect?'

\section{Analysis and Synthesis}

Three types of task may be asked with respect to engineering products (systems):

(a) Analysis: given a structure, find its behaviour and other properties; an entity (a whole) is decomposed and explored, using causality as a premiss, and mathematical models - e.g. the engineering sciences;

(b) Synthesis: given the desired behaviour and other requirements, find a structure that satisfies the behaviour and requirements - usually one of several possible structures; explore, select and unite the (often opposing or contradictory) units, and moderate and overcome any contradictions, using finality as the aim, including creativity, to find and select among candidate solutions for a TP(s) and/or TS(s) - design engineering; and

(c) Black box problem, Identification: given a system, of which the structure is unknown or only partly known, find its behaviour (and its inputs and outputs), and possibly its structure.

Both synthesis and the black box problem must be accompanied by analysis. Analysis (analyzing) involves finding the causes and parameters of the actual or anticipated behaviour of an existing or planned structure, and/or its (detail) values. This can be a verbal and graphical analysis, e.g. to formulate TS-internal and cross-boundary functions, or a mathematical analysis to find a value of a dependent variable from given or assumed independent variables. In reality, analysis is in essence a one-to-one 'singleanswer' transformation. Synthesis (synthesizing) involves finding suitable means to achieve a goal, e.g. a proposed (function-, organ- and/or constructional) structure that will show a required behaviour - this is not a simple inversion of analysis, it goes far beyond a reversal, it is almost always a transformation that deals with alternative means and arrangements, a one-tomany (or few-to-many) transformation. Synthesizing is the more difficult kind of action.

Synthesis and product development consists of establishing and assigning the product's internal properties from the required external properties [12]. The internal properties show a complex relationship to the external properties, compare figure 3 . In analysis, these relationships are known and can be determined. In synthesis, 'inverting the relationships' can and usually does result in conflicts which must be resolved, and which are not predictable in advance.

The need for connections, interactions and context of engineering science can be demonstrated on an example of thermodynamics - essentially expanding and compressing gases with heat and work addition and extraction. The connection to containment is usually not made obvious, but that containment needs strength at the prevailing temperature, possible guidance of flow (gas dynamics), etc.

A generally held conviction wrongly claims that all synthesis is 'creative' and 'intuitive' - yet knowledge and many methods can help in synthesis. The term 'creative synthesis' should be used only for new and previously unknown results of synthesis, e.g. radical patents, or a synergistic formation.

The arrangement of information for the two purposes of analysis and synthesis should be different, unless selective search by computer is used. Analysis can use the arrangement of the traditional engineering sciences, synthesis usually needs an arrangement according to achieved output effects of the operators.

\section{Iterative Procedure}

Further (evoked) requirements will emerge during this synthesis (see also stage P8 in section 2), always searching for possible alternatives, e.g. cooling (fins on the casing?); lubricating (filling, draining, measuring of oil level, transporting oil to gear faces and bearing locations?); transporting (hoisting facilities?); noise reduction (isolation?); etc. This demonstrates the need for iterative solving of design problems.

These functions, by which the TS, the operand and the operational situation interact, indicate the analytical methods from the engineering sciences that can help to evaluate a proposed TS(s), and to establish the needed sizes (and sometimes forms) of constructional parts. At first a 'quick and dirty' estimate is made [21], 


\section{Figure 3 Technical Systems: Survey of Relationships Among Classes of Properties [2]}

followed by a 'static' view, e.g. maximum stress from static loading. If needed, a 'dynamic' investigation and simulation can follow, e.g. vibration behaviour, for which a four-pole simulation can be employed [22].

For engineering designers to start their design work, and to achieve the necessary values of the properties, they must have available information about quantitative and pseudo-quantitative relationships of individual properties. For instance, the strength of a TS (and of its constructional parts) is usually a basic requirement for its ability to function, its durability and reliability - an expression of finality. Strength in turn depends on the structure and form, and the dimensions (sizes) of the TS (and of its constructional parts) - an expression of causality. C. Bach (1906) solved the questions of strength by recommending calculation methods for loading conditions, applied stress, allowable maximum stress, and guidelines for factors of safety, to establish the necessary dimensions, forms (shapes) and surface qualities. These are useful as first estimates. Newer analytical methods (e.g. FEM) provide greater accuracy of prediction, but at increased cost of design engineering. The validity of these calculations, and the assumptions made to enable them (e.g. that a calculation method is 'conservative'), is really only shown when the TS is operating. Acceptance tests after manufacture of a TS can confirm some of the calculations and assumptions. Corrections in the design properties (classes Pr10,
Pr11 and Pr12) can best be made if a recognized 'error-quantity' can be fed back from a more positive determination of the achieved values of other properties, iteration. A different situation emerges within the operation 'search for solutions', where the goal is to establish individual properties. The solution to this sub-problem consists of establishing (synthesizing) certain manifestations and values for the relevant property. E.g. to establish the strength of a constructional part, select a suitable material, and an appropriate size (dimension) to withstand the applied stress. The comparison of the stress (as determined from the engineering science of stress analysis) with a permitted value (the stress resistance capability of the material) for the individual raw materials allows a statement about whether the strength is adequate for the proposed duty, usually expressed as a 'factor of safety'. Similar considerations are valid for other characteristics which are determined by laws of a certain discipline. Methods for many of the analytical and/or predictive determinations are prescribed by standards and codes of practice. Comparing an assumed loading with a limiting condition is often called 'calculation', mathematical analysis play a role.

\section{Closure}

Design engineering is such an important element of human activity, that it should feature in all years of 
study in engineering education. The processes of iterative and recursive design actions should be an integral part of engineering education at all levels. Especially the processes of synthesis should be emphasized, even in the analytical engineering science courses. This then supports life-long learning to allow a practitioner to move higher in the scale of expertise and competenies [9]. The understanding delivered by EDS should also help coordinate subjects in a curriculum.

\section{References}

[1] Hubka, V., \& Eder, W.E. (1996) Design Science: Introduction to the Needs, Scope and Organization of Engineering Design Knowledge, London: Springer_Verlag, http://deseng.ryerson.ca/DesignScience/.

[2] Eder, W.E. \& Hosnedl, S. (2008) Design Engineering: A Manual for Enhanced Creativity, Boca Raton: CRC Press

[3] Eder, W.E., Hubka, V. and Benabdallah, H. (2004) 'Educating for Engineering Design using Design Science', in Proc. Inaugural CDEN Design Conference, McGill University, Montreal, July 29 - 30, 2004, on CD-ROM

[4] Eder, W.E. (2005) 'Machine Elements - Revision and Outlook for Design Education', in Proc. Second CDEN International Conference, University of Calgary, Alberta, 18-19 July 2005 at Kananaskis Resort, paper 10006 on CD-ROM

[5] Eder, W.E. (2005) 'Application of Design Methodology for Education', in Proc. Second CDEN International Conference, University of Calgary, Alberta, 18-19 July 2005 at Kananaskis Resort, paper 10007 on CD-ROM

[6] Eder, W.E. (2006) 'Properties of Technical Systems - Key to Crossing Design Boundaries', in Proc. CDEN Conference 2006 Toronto, 2426 July 2006, on CD-ROM

[7] Eder, W.E. (2006) 'Case Study in Design Engineering', in Proc. CDEN Conference 2006 Toronto, paper 28, on CD-ROM

[8] Eder, W.E. (2007) 'Design Engineering - Not Just Applied Science', in Proc. CDEN/CCEE Canadian Design Engineering Network and Canadian Conference on Engineering Education, 22-24 July 2007, U. of Manitoba, Winnipeg, Manitoba, on CD-ROM

[9] Eder, W.E. (2008) 'A Case for Systematic and Methodical Design Engineering', in Proc. CDEN Conference 2008 Halifax, (in review)

[10] Hubka, V., \& Eder, W.E. (1988) Theory of Technical Systems, New York: Springer_Verlag,
[11] Hubka, V. and W.E. Eder (1992) Engineering Design, Zürich: Heurista $\left(2^{\text {nd }}\right.$ edition of Hubka, V., Principles of Engineering Design, London: Butterworth Scientific, 1982, translated and edited by W.E. Eder from Hubka, V., WDK 1 Allgemeines Vorgehensmodell des Konstruierens (General Procedural Model of Designing), Zürich, Heurista, 1980)

[12] Eder, W.E. and Hosnedl, S. (2008) 'Properties Of Technical Systems - Augmenting a Legacy of Vladimir Hubka', Jnl. Eng. Design, (in review)

[13] Weber, C. and Vajna, S., 'A New Approach to Design Elements (Machine Elements)'. In WDK 25 - Proc. ICED 97 Tampere, Tampere University, Vol. 3, 1997, p. 685-690

[14] Eder, W.E., 'Machine Elements - Integration Of Some Proposals'. In Proc. AEDS 2004 Workshop, The Design Society - Special Interest Group Applied Engineering Design Science, 11-12 Nov 2004, Pilsen, Czech Republic, 2004; on CD-ROM

[15] Eder, W.E., 'Machine Elements - Revision and Outlook for Design Education'. In Proc. Second CDEN International Conference, University of Calgary, 18-19 July 2005 at Kananaskis Resort, paper 10006, 2005; on CD-ROM

[16] Nevala, K. Content-based Design Engineering Thinking, Academic Dissertation, University of Jyväskalä, Finland, Jyväskalä: University Printing House, 2005; http://cc.oulu.fi/ nevala

[17] Eder, W.E. (ed) (1996) WDK 24 - EDC Engineering Design and Creativity -Proceedings of the Workshop EDC, Pilsen, Czech Republic, November 1995 Zürich: Heurista

[18] Eder, W.E., 'Reflections About Reflective Practice', in Proc. International Design Conference - Design 2004, Dubrovnik, May 18 21, 2004, p. 177-182

[19] Schön, D.A., The Reflective Practitioner: How Professionals Think in Action, Basic Books, New York, 1983

[20] Schön, D.A., Educating the Reflective Practitioner: Towards a New Design for Teaching and Learning in the Professions, San Francisco: Jossey-Bass, 1987

[21] Rheinfrank, J.J., ASEE-DEED BULLETIN, Vol. 14 No. 1,1989, p. 12

[22] Weber, C., Lecture Presentation, sections SME00 - SME06 and ME0102, 2005. URL http://www.cad.unisaarland.de/index.html ?rubrik=lehre/vorlesung\&site=vorlesung 